$\underline{\xi}=$ 잘

\title{
Stress distributions in maxillary central incisors restored with different high-stiffness post models: 3-D FEA
}

\author{
Bassam Srayeddin ${ }^{1}$, Ali Almuntashri ${ }^{2}$ \\ ${ }^{1}$ Dental Department, King Saud bin Abdulaziz University for Health Sciences, Ministry of National Guard Health Affairs, Riyadh, Saudi \\ Arabia \\ ${ }^{2}$ King Abdullah International Medical Research Center, Ministry of National Guard Health Affairs, Riyadh, Saudi Arabia \\ *Corresponding author E-mail:
}

\begin{abstract}
Background: Dental root posts are recommended for endodontically treated weakened teeth.

Objectives: The present computational FEA study aims to evaluate the effect of material and design of the post on the stress distribution under load in different root canal shapes of endodontically treated maxillary central incisor (MCI).

Methods: Three-dimensional models of (MCI) were created by using CAD modeling software and divided into two groups. Group-I comprised five models of a weakened root restored using different post materials (stainless steel, titanium, gold-alloy, Ni-Cr, and zirconium). Group-II: involved four models of (MCI) with two different root canal shapes (small and wide) restored using cylindrical (C-Post) and two-stage tapered (T-Post) posts. Each tooth model was subjected to a $100 \mathrm{~N}$ oblique load at the palatal surface of the crown. Von Mises equivalent stresses on dentin and post, as well as shear stresses on the post cement, were evaluated.

Results: In Group-I: Ni-Cr produced the lowest stress values on the dentin, where titanium and gold-alloy posts produced the lowest stresses in the post and post/root interfaces. In Group-II: Roots restored with a T-Post showed a lower concentration stress in the dentin and lower shear stresses in the cement layer compared with those restored with a C-Post.

Conclusion: The geometry of the post and the corresponding material play an important role in the stress behavior of restored teeth. The use of titanium or gold-alloy T-Posts seems a good way to improve the stress distribution profile and reduce the risk of restoration failure.
\end{abstract}

Keywords: Prefabricated Post; Tapered Post; Post Material; Stress Distribution; FEA

\section{Introduction}

Root canal-treated teeth are weaker than vital teeth, and exhibit a high risk of biomechanical failures due to filling preparations, endodontic procedures, or extensive loss of tooth structure (De Castro Albuquerque et al. 2003; Tang et al. 2010). A root post is generally recommended for a tooth affected by a significant loss of coronal tissues, to provide higher retention to the core and the final restoration (Schwartz and Robbins 2004). Root posts can be classified into two categories; prefabricated and customized cast posts (can be created in a laboratory to fit the original shape of the root canal preparation). Recently, however, prefabricated posts have been used preferentially to cast posts because they are easier to use and less expensive to make (Gonzalez-Lluch et al. 2009). Prefabricated posts are available in a variety of materials and properties (such as metallic vs. non-metallic), as well as different diameters and designs (such as parallel vs. tapered) (Genovese et al. 2005; Schwartz and Robbins 2004).

The material type of the root post significantly influences the fracture resistance and stress distribution pattern of the final restoration (De Castro Albuquerque et al. 2003; Dejak and Mlotkowski 2011; Durmus and Oyar 2014; Maroulakos et al. 2015; Oyar 2014). Even though several studies have analyzed the biomechanical behavior of different post-and-core systems, the restoration of root canal-treated teeth still presents several unresolved aspects, and no consensus has been reached in the literature on the best material or technique to use for this purpose (De Castro
Albuquerque et al. 2003; Li X et al. 2008; Ortega et al. 2004). However, because of their favorable performance in decreasing dentin stress during masticatory loads, many authors recommend using posts with a high modulus of elasticity to restore weakened endodontically treated teeth (Asmussen et al. 2005; Dejak and Mlotkowski 2011; Durmus and Oyar 2014; Seo et al. 2009). Furthermore, numerous in vitro studies showed that teeth restored with high-stiffness post materials have a higher fracture resistance than teeth restored with other post systems (Balkaya and Birdal 2013; Maroulakos et al. 2015)

In addition to the material type, the shape of the post can affect the amount of stress placed on the tooth. Also, the authors have different views on this subject: for instance, many studies showed conflicting in the outcomes of parallel versus tapered prefabricated posts. (Asmussen et al. 2005) find that the parallel post produced lower stress in dentin compared to the tapered shape, whereas (De Castro Albuquerque et al. 2003) conclude that the post shape has a small effect on the stress concentrations in dentin. However, (Uddanwadiker et al. 2007) demonstrate that the tapered post with a minimum taper induces lower stress in dentin and better retention compared to the parallel post. Moreover, according to (Maroli et al. 2017) the conical posts have higher fracture strength than those with the parallel shape.

Different methods have been used to evaluate the failure rate of teeth restorations based on various post systems, including clinical and experimental approaches, as well as theoretical methods such as finite element analysis (FEA). FEA is a computational method for the numerical analysis of complex structures based on the 
properties of the materials involved. This powerful technique, which has been employed by several authors (Asmussen et al. 2005; Dejak and Mlotkowski 2011; Genovese et al. 2005; Gonzalez-Lluch et al. 2009; Li X et al. 2008; Seo et al. 2009), is extremely useful for analyzing mechanical features of biomaterials and human tissues that are difficult to inspect in vivo (Fu et al. 2010; Seo et al. 2009; Wakabayashi et al. 2008). FEA method provides different analysis tests on stress distribution under loads to predict failure pattern of the structures such as von Mises stress and shear stress criterions. The von Mises stress criterion is a strong indication of the possibility of damage occurrence (Asmussen et al. 2005; Durmus and Oyar 2014), where shear stresses can indicate the sliding effects between restoration components and post detachment (Genovese et al. 2005).

Several high-stiffness materials, including traditional materials such as stainless steel (Ss), gold alloy ( $\mathrm{Au})$, and nickel chromium (Ni-Cr) and comparatively the most recent titanium (Ti) and zirconium $(\mathrm{Zr})$ were used in this filed to make various type of root posts. Therefore, additional studies are necessary to determine how different post designs and materials affect the stress distribution of the root-post and core system. The aim of this FEA study was to evaluate the stress behavior of maxillary central incisors restored with five high-stiffness post materials ( $\mathrm{Ss}, \mathrm{Ti}, \mathrm{Au}, \mathrm{Ni}-\mathrm{Cr}$, and $\mathrm{Zr}$ ) and to compare the effect of two post designs (cylindrical and two-stage tapered posts (C-Post and T-Post, respectively)) on the stress distribution in different root canal configurations.

\section{Material and methods}

\subsection{D models generation}

A three-dimensional (3D) model of a maxillary central incisor was built using computer-aided design (CAD) software (Autodesk Inventor Professional 2012, Autodesk, Inc.) according to literature data (Nelson SJ and M. 2010). The crown was $10.5 \mathrm{~mm}$ long, 8.5 $\mathrm{mm}$ in mesio-distal width, and with a root length of $13 \mathrm{~mm}$.

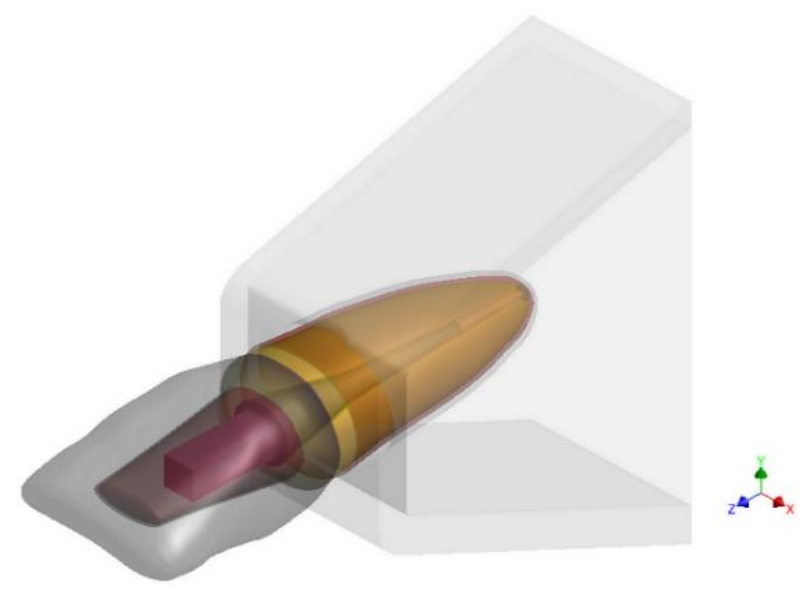

Fig. 1: 3D Tooth Model (SC2) with Bone and PDL.

Ten components [root, post, gutta-percha filling, post-cement, composite core, crown-cement, crown, periodontal ligament (PDL), cancellous bone, and cortical bone] were generated separately and then assembled in the final model (Fig.1). The root was simulated with $1 \mathrm{~mm}$ of ferrule high coronal to the cementoenamel junction and restored with a post, composite core and a leucitereinforced ceramic crown (IPS Empress Esthetic; Ivoclar Vivadent $\mathrm{AG})$. The crown was retained with a $0.1 \mathrm{~mm}$-thick resin luting cement (Variolink II; Ivoclar, Vivadent AG). The average distance between the crest of the alveolar bone and the cementoenamel junction in young adults is almost $1 \mathrm{~mm}$ (Newman MG et al. 2015). A $0.18 \mathrm{~mm}$ layer was modeled as PDL in adults (aged 3250) (Newman MG et al. 2015). The cancellous bone was covered by 1.59 and $1.95 \mathrm{~mm}$ thicknesses of buccal and lingual cortical bone (Katranji et al. 2007), respectively, and a $0.25 \mathrm{~mm}$ thickness of compact bone was considered the lamina dura layer. The root canal was prepared according to the post shape with $0.1 \mathrm{~mm}$ wider size. The post-cement layer was created with a thickness of 0.1 $\mathrm{mm}$ and the remaining space between post and root canal wall was filled with cement. Zinc phosphate cement was used for the metal posts ( $\mathrm{Ss}, \mathrm{Ti}, \mathrm{Au}$, and $\mathrm{Ni}-\mathrm{Cr}$ ) whereas the resin luting cement was used for $\mathrm{Zr}$ post. The periodontal tissues supporting the tooth model were cut mesially and distally according to the widest width of the crown.

Table 1: Configuration of the FEA Models

\begin{tabular}{|c|c|c|c|c|c|}
\hline Group & $\begin{array}{l}\text { Model } \\
\text { number }\end{array}$ & $\begin{array}{l}\text { Model } \\
\text { label }\end{array}$ & $\begin{array}{l}\text { Post } \\
\text { type }\end{array}$ & $\begin{array}{l}\text { Post } \\
\text { material }\end{array}$ & $\begin{array}{l}\text { Root canal } \\
\text { shape }\end{array}$ \\
\hline \multirow{5}{*}{ I } & 1 & $\mathrm{SsP}$ & T-Post & Ss & S-Canal \\
\hline & 2 & $\mathrm{TiP}$ & T-Post & $\mathrm{Ti}$ & S-Canal \\
\hline & 3 & $\mathrm{GaP}$ & T-Post & $\mathrm{Au}$ & S-Canal \\
\hline & 4 & $\mathrm{NcP} *$ & T-Post & $\mathrm{Ni}-\mathrm{Cr}$ & S-Canal \\
\hline & 5 & $\mathrm{ZrP}$ & T-Post & $\mathrm{Zr}$ & S-Canal \\
\hline \multirow{4}{*}{ II } & 6 & SC1 & C-Post & $\mathrm{Ni}-\mathrm{Cr}$ & S-Canal \\
\hline & 7 & $\mathrm{SC} 2 *$ & T-Post & $\mathrm{Ni}-\mathrm{Cr}$ & S-Canal \\
\hline & 8 & WC1 & C-Post & $\mathrm{Ni}-\mathrm{Cr}$ & W-Canal \\
\hline & 9 & WC2 & T-Post & $\mathrm{Ni}-\mathrm{Cr}$ & W-Canal \\
\hline
\end{tabular}
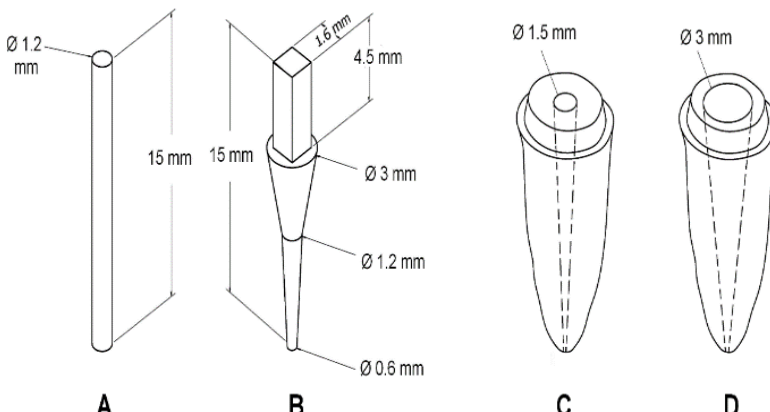

C

$D$

Fig. 2: Post Models and Root Canal Shapes Before Prepared. (A) C-Post. (B) T-Post. (C) S-Canal. (D) W-Canal.

According to the literature, the length of the post should be equal to $75 \%$ of the root length or at least match the length of the crown (Schwartz and Robbins 2004). In the present model, the total length of the post was set to $15 \mathrm{~mm}$, and $10.5 \mathrm{~mm}$ (equal to the crown length) were inserted into the prepared root canal. At the root apex level, the model included $3.5 \mathrm{~mm}$ of gutta-percha filling as an apical seal (Abramovitz et al. 2001).

Nine 3D tooth models, divided into two groups, were created (Table 1). Group-I included five tooth models corresponding to five different root post materials $(\mathrm{Ss}, \mathrm{Ti}, \mathrm{Au}, \mathrm{Ni}-\mathrm{Cr}$, and $\mathrm{Zr}$ ) restored with a T-Post, composite core, and crown. Group-II included two different designs of prefabricated root posts (C-Post and T-Post) inserted in two different root canal configurations of the maxillary central incisor: small canal (S-Canal) and wide canal (W-Canal) (Fig.2 and Fig.3).
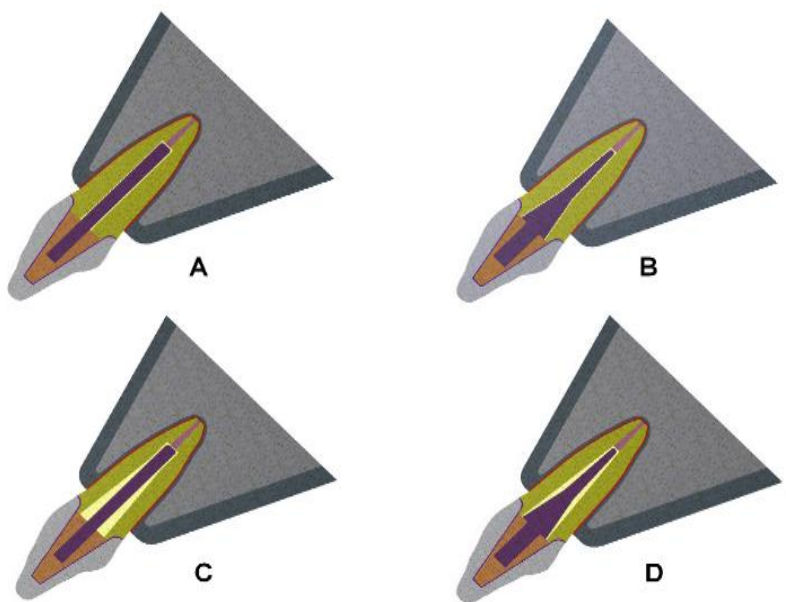

Fig. 3: Bucco-Palatal Sagittal Section View of: (A) SC1, (B) SC2, (C) WC1, and (D) WC2 Model. 
Table 2: Isotropic Mechanical Properties of the Component Materials

\begin{tabular}{|c|c|c|c|}
\hline Component/Material & $\begin{array}{l}\text { Elastic mod- } \\
\text { ulus (MPa) }\end{array}$ & $\begin{array}{l}\text { Poisson's } \\
\text { Ratio } \\
\end{array}$ & References \\
\hline Stainless steel post & 200000 & 0.33 & $\begin{array}{l}\text { (De Castro } \\
\text { Albuquerque et al. } \\
\text { 2003) }\end{array}$ \\
\hline Dentin & 18600 & 0.31 & $\begin{array}{l}\text { Albuquerque et al. } \\
\text { 2003) }\end{array}$ \\
\hline $\begin{array}{l}\text { Crown leucite ce- } \\
\text { ramics }\end{array}$ & 65000 & 0.19 & $\begin{array}{l}\text { (Dejak and } \\
\text { Mlotkowski 2011) }\end{array}$ \\
\hline Variolink II cement & 8300 & 0.35 & $\begin{array}{l}\text { (Dejak and } \\
\text { Mlotkowski 2011) }\end{array}$ \\
\hline Gutta-percha & 140 & 0.45 & (Oyar 2014) \\
\hline $\begin{array}{l}\text { Zinc-oxide phos- } \\
\text { phate }\end{array}$ & 22400 & 0.35 & $\begin{array}{l}\text { (Durmus and Oyar } \\
\text { 2014) }\end{array}$ \\
\hline Ni-Cr Alloy & 205000 & 0.33 & $\begin{array}{l}\text { (Durmus and Oyar } \\
\text { 2014) }\end{array}$ \\
\hline Cortical bone & 13700 & 0.30 & $\begin{array}{l}\text { (Gonzalez-Lluch et } \\
\text { al. 2009) }\end{array}$ \\
\hline Cancellous bone & 1370 & 0.30 & $\begin{array}{l}\text { (Gonzalez-Lluch et } \\
\text { al. 2009) }\end{array}$ \\
\hline Periodontal ligament & 68.9 & 0.45 & $\begin{array}{l}\text { (Gonzalez-Lluch et } \\
\text { al. 2009) }\end{array}$ \\
\hline $\begin{array}{l}\text { Zirconia ceramic } \\
\text { post }\end{array}$ & 200000 & 0.23 & (Seo et al. 2009) \\
\hline Titanium post & 120000 & 0.33 & $\begin{array}{l}\text { (Asmussen et al. } \\
\text { 2005) }\end{array}$ \\
\hline Gold alloy & 93000 & 0.33 & $\begin{array}{l}\text { (Mahmoudi et al. } \\
\text { 2012) }\end{array}$ \\
\hline Composite & 12000 & 0.3 & $\begin{array}{l}\text { (Mahmoudi et al. } \\
\text { 2012) }\end{array}$ \\
\hline
\end{tabular}

\subsection{Finite element analysis}

The final 3D models were imported into the FEA software (ANSYS ver.15, Workbench; ANSYS, Inc.). All the materials and structures were assumed to be linear, elastic, homogeneous, isotropic, and bonded together with surface-to-surface contacts. The mechanical properties of all component materials were taken from the literature and are shown in Table 2.

Because of the complicated geometry of the tooth, a tetrahedral mesh is typically used in FEA studies of these systems (PérezGonzález A et al. 2011). The SC1 tooth model was composed of 185546 elements, 316543 nodes; the SC2 model: 186213 elements, 318358 nodes; the WC1 model: 192297 elements, 327374 nodes; the WC2 model: 193989 elements, 330645 nodes. The accuracy of the models were checked by mesh convergence analysis of $2 \%$.

Each model was constrained at the base and sliced along the mesial/distal surfaces to simulate the model, as in the mouth. A $100 \mathrm{~N}$ static occlusal was applied on the palatal face of the crown at a $45^{\circ}$ angle (De Castro Albuquerque et al. 2003) with respect to the longitudinal axis of the tooth, as indicated in (Fig.4). The von Mises equivalent stress (VMS) on post and root (dentin) were investigated and the maximum shear stresses $(\tau)$ on the post cement were calculated on all directions (YZ, XZ, and YX) for all models of the two groups. A total deformation criterion was also adopted to evaluate the nodal displacements for each model.

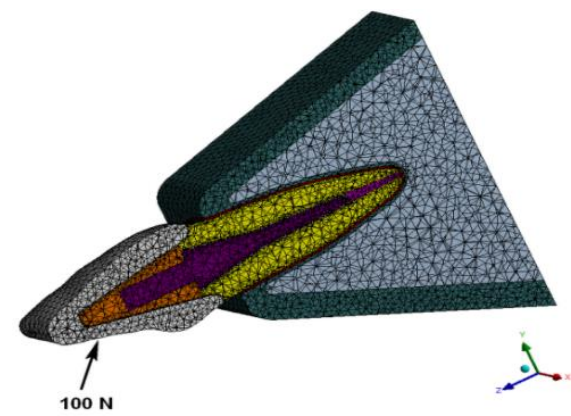

Fig. 4: Sagittal Section of the Finite Element Mesh of the SC2 Model, Showing the Load Conditions.
Table 3: Maximum Von Mises Equivalent Stress (VMS) Values in Root and Post (Mpa), and Maximum Shear Stress (T) in Post Cement (Mpa)

\begin{tabular}{lllllllll}
\hline & & \multicolumn{3}{c}{ VMS } & \multicolumn{3}{c}{$\tau$ (Post cement) } \\
\hline \multirow{2}{*}{ Group } & $\begin{array}{l}\text { Model } \\
\text { number }\end{array}$ & $\begin{array}{l}\text { Model } \\
\text { label }\end{array}$ & Root & Post & $(\tau) \mathrm{yz}$ & $(\tau) \mathrm{xy}$ & $(\tau) \mathrm{xz}$ \\
& 1 & SsP & 28.77 & 118.42 & 5.219 & 4.976 & 3.475 \\
& 2 & TiP & 30.25 & 70.35 & 5.088 & 4.635 & 2.835 \\
I & 3 & GaP & 30.88 & 53.55 & 4.995 & 4.361 & 2.476 \\
& 4 & NcP & 28.69 & 121.35 & 5.224 & 4.982 & 3.517 \\
& 5 & ZrP & 29.05 & 125.15 & 5.327 & 3.094 & 3.179 \\
& 6 & SC1 & 31.75 & 93.92 & 7.892 & 3.427 & 3.459 \\
II & 7 & SC2 & 28.69 & 121.35 & 5.224 & 4.982 & 3.517 \\
& 8 & WC1 & 31.81 & 92.08 & 8.353 & 3.083 & 3.741 \\
& 9 & WC2 & 27.92 & 119.16 & 5.488 & 4.962 & 3.33 \\
\hline
\end{tabular}

\section{Results}

We modeled teeth restored with post composed of $\mathrm{Ss}, \mathrm{Ti}, \mathrm{Au}, \mathrm{Ni}-$ $\mathrm{Cr}$, and $\mathrm{Zr}$ and simulated a crown pressure of $100 \mathrm{~N}$. Table 3 lists the calculated values of maximum von Mises stress on the root and post and maximum shear stress on of the post-cement layer for the two groups, where the Table 4 shows the total deformation values of the post and tooth models. In all cases, the stress of dentin was concentrated on the facial surface of the coronal part of the root (Fig.5 and Fig.6).

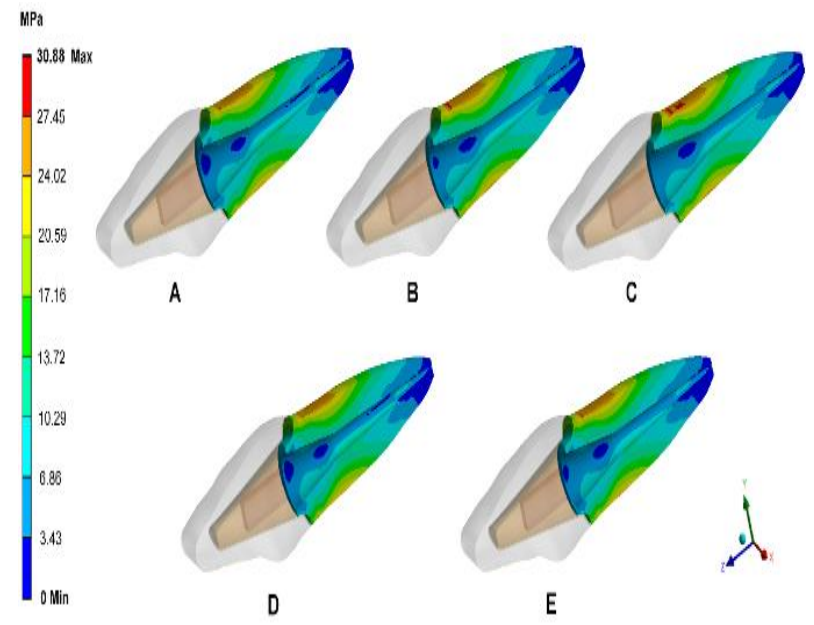

Fig. 5: Von Mises Equivalent Stress Comparison in Weakened Roots of Group-I: (A) SsP Model, (B) TiP Model, (C) GaP Model, (D) NcP Model, And (E) ZrP Model.

Table 4: Maximum Displacement Values of Post and Tooth Models (Mm)

\begin{tabular}{lllcc}
\hline Group & Model number & Model label & Post & Tooth \\
\hline \multirow{4}{*}{ I } & 1 & SsP & 0.0405 & 0.0629 \\
& 2 & TiP & 0.0411 & 0.0640 \\
& 3 & GaP & 0.0414 & 0.0645 \\
& 4 & NcP & 0.0404 & 0.0629 \\
& 5 & ZrP & 0.0407 & 0.0633 \\
II & 6 & SC1 & 0.0416 & 0.0651 \\
& 7 & SC2 & 0.0404 & 0.0629 \\
& 8 & WC1 & 0.0415 & 0.0648 \\
& 9 & WC2 & 0.0404 & 0.0629 \\
\hline
\end{tabular}

As discussed above, Group-I comprises models of a restored tooth involving T-Posts of different materials inserted in a small root canal (S-Canal); The Ni-Cr and $\mathrm{Au}$ posts produced the lowest and highest VMS on the dentin, respectively, with only a 7.7\% difference between the two values. The stress values on the post increased with increasing modulus of elasticity of the post material. The lowest stress was recorded when the gold alloy was used, whereas the zirconium led to a $133 \%$ higher stress value on the post (Table 3. Fig.7). the maximum shear stress $(\tau)$ values on the post-cement layer also increased with increasing modulus of elasticity of the post material. The lowest shear stresses on the cement were recorded for $\mathrm{Au}$ and $\mathrm{Ti}$ materials, whereas $\mathrm{Ni}-\mathrm{Cr}$ and $\mathrm{Zr}$ materials led to the highest stress values (YZ plan). The total de- 
formations of the post and tooth models showed a slight increase with decreasing modulus of elasticity of the post material (Table 4).

The models in Group-II combined two post designs and two root canal shapes. Lower VMS on the root were obtained for the TPost-based models. The stress values on the dentin were $10.6 \%$ lower in the SC2 and $14 \%$ in the WC2 model. Higher $(\tau)$ stresses on the post cement were found when the C-Post was used (YZ plan), and the highest values were recorded for the WC1 model. Severe interfacial shear stress concentrations were identified in two regions, active values at the coronal root and passive values at the apical third of the root interfaces (Fig.8). T-Post dissipated interface shear stress excellently on the coronal part of the root. Higher total deformations of the teeth and posts were recorded when using the C-Post and the highest deformation values were found for the SC1 model (Table 4).
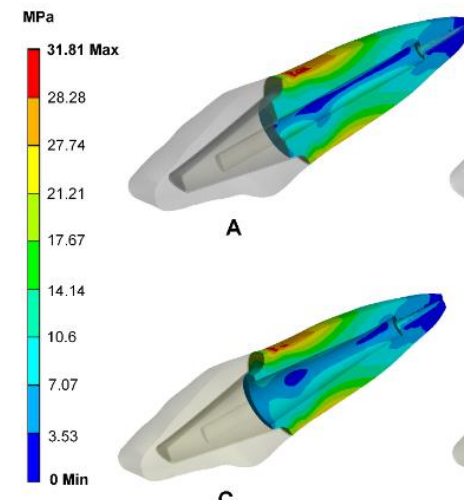

A
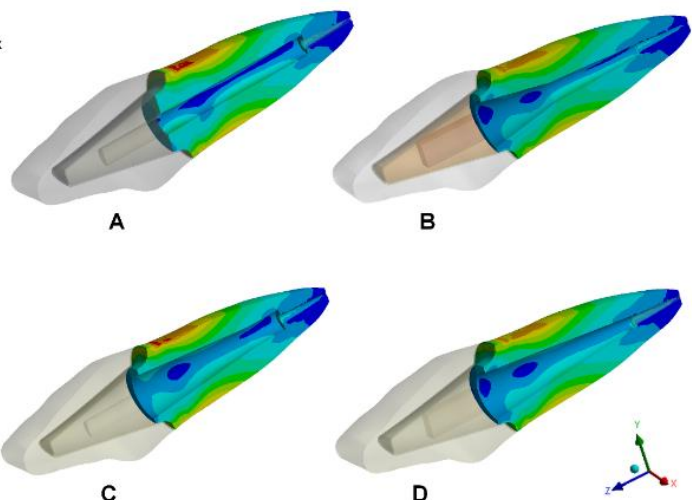

Fig. 6: Von Mises Equivalent Stress Comparison in Weakened Roots of Group-II: (A) SC1 Model, (B) SC2 Model, (C) WC1 Model, and (D) WC2 Model.

\section{Discussion}

The use of root post to restore endodontically treated tooth creates unnatural restoration components since the canal is filled with a material that has defined stiffness, unlike the natural pulp tissue, making it impossible to recreate the original stress distribution pattern within a tooth (Durmus and Oyar 2014). A proper stress distribution profile of the compound root, post, and core is necessary to minimize the probability of restoration failure. In this study, the FEA method was used to evaluate the influence of the post material and geometry on the stress distribution in endodontically treated teeth. Von Mises stress was the chosen criterion to assess the potential failure of the root and post, as well as shear stress criterion to evaluate the risk of post detachment. In line with previous studies (Durmus and Oyar 2014; Mahmoudi et al. 2012; Oyar 2014; Uddanwadiker et al. 2007), the present analysis revealed higher dentin stress concentrations in the coronal third of the root on the facial surfaces of the teeth. This study found that the use of different high-stiffness post materials caused only minor changes in the stress on the dentin. This result is consistent with previous studies by (Genovese et al. 2005), (Fu et al. 2010), and (Mahmoudi et al. 2012) which reported a negligible influence of rigid post materials on the stress concentration in the remaining tooth structures. In contrast, the use of different post materials resulted in significantly different stresses on the post and post-dentin interfaces. The equivalent stresses on the posts increased with increasing elastic modulus of the material; similar results have been observed in other studies (Asmussen et al. 2005; Dejak and Mlotkowski 2011; Oyar 2014).

Due to the high modulus of elasticity of the posts, the occlusal loads were transmitted directly to the post and post-dentin interfaces. Stresses located at the post-dentin interface may negatively affect post retention (Fu et al. 2010; Seo et al. 2009), therefore reducing these stresses is vital to minimize the possibility of displacement of the post. As is clear, shear stresses will contribute to detach the post because they produce relative sliding between post-core and dentin (Genovese et al. 2005). This study showed that Au material recorded the lowest stress in the post as well as lowest shear stresses in the cement layer, this may lead to increases in retention of $\mathrm{GaP}$ post compared to the other tested models in Group-I. The result was consistent with the FEA finding of (Mahmoudi et al. 2012) in that a prefabricated gold alloy post generated lower stress at post-dentin interface compared with $\mathrm{Ni}-\mathrm{Cr}$ and titanium posts, on stress distribution in posterior teeth. Furthermore, a retrospective clinical study evaluated the failure rate of custom cast posts and showed that the most common complication was loss of retention of the post and cores, and High-gold-content posts had a lower risk of failure than posts made from semiprecious alloy (Balkenhol et al. 2007).

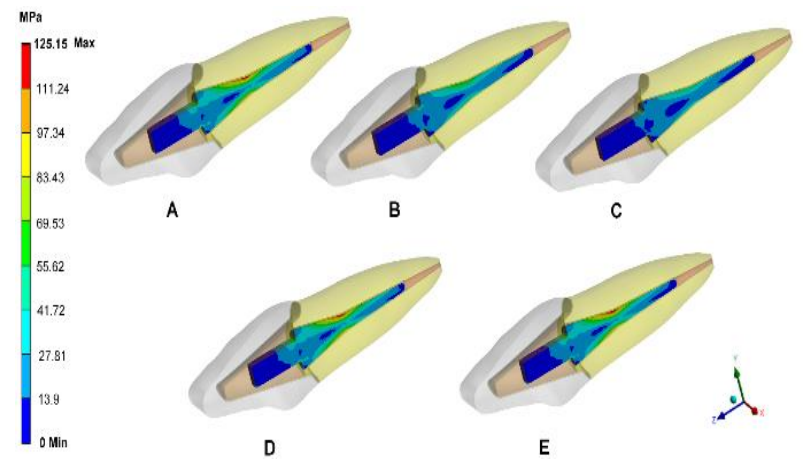

Fig. 7: Von Mises Equivalent Stress Comparison in the Posts of Group-I (A) SsP Model, (B) TiP Model, (C) GaP Model, (D) NcP Model, and (E) ZrP Model.

The present work also found that the post geometry has a significant influence on the stress concentration in the dentin and post. The FEA results showed that the T-Post absorbed more stress, and caused a $\sim 10-14 \%$ reduction in stress on the dentin under oblique load as well as a lower shear stresses on the cement layer, compared to the C-post. Furthermore, the T-Post provided more dissipation of the interface stress on the coronal part of the root, and distribute functional loading over a larger area of the remaining root structure compared to the C-Post. Therefore, more biomechanically favorable stress distribution in the root can be achieved when using T-post model. These different behaviors may be due to the two-stage tapered shape of the T-Post and to the $1.8 \mathrm{~mm}$ difference between the diameters of the two posts at the root ferrule level. In general tapered post provides superior adaptability to different root canal configurations, thus permitting optimal preservation of tooth structure and reducing the risk of post perforation in the apical region (Schwartz and Robbins 2004). Therefore, less cement needs to be used to fix the tapered post compared with the cylindrical shape.

Several FEA studies were conducted and compared the behavior of different post shapes on stress distribution of weakened roots; however, there are no data available on comparisons between the two- stage tapered post and the other root post models. However, the result is in line with the finding of (Asmussen et al. 2005) who demonstrated that a post with smaller diameter produces more stress on the root, and the author suggested to use a wide-diameter post as possible to restore weakened roots. Furthermore, the result conforms (Uddanwadiker et al. 2007) who concluded that a tapered post with a minimum taper produces lower stress and better retention compared with a cylindrical post. On the other hand, this result contradicted that of (De Castro Albuquerque et al. 2003) which stated that the maximum stress values in restored teeth were insensitive to the post shape.

The present theoretical study has some limitations, as all materials were assumed to be linearly elastic, homogeneous, isotropic, and ideally bonded together. However, the physical properties of biological structures are approximate, and the tooth structures are not homogeneous or isotropic (De Castro Albuquerque et al. 2003; Dejak and Mlotkowski 2011). Further experimental and clinical tests are necessary to evaluate the performance of different root post systems. 


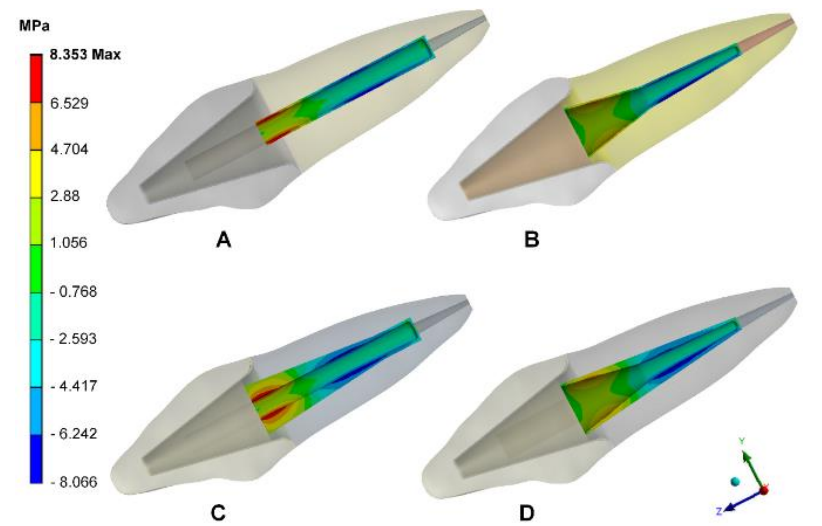

Fig. 8: Maximum Shear Stress Comparison in Post-Cement of Group-II (YZ Plan): (A) SC1 Model, (B) SC2 Model, (C) WC1 Model, and (D) WC2 Model-the Highest Values Are Marked in Red Color.

\section{Conclusions}

Within the limitations of this study, as discussed above, the following conclusions could be drawn:

1) The geometry of the post and the corresponding material play an important role in the stress magnitude and distribution in the post, dentin, and post/dentin interfaces.

2) Titanium and gold alloy appear to be the most reliable metallic materials for post systems because they generate lower amounts of stress at the post and post/dentin interfaces.

3) The shape of the post significantly alters the stress concentration in dentin, and the two-stage tapered post would be a very interesting choice to restore weakened teeth.

\section{Acknowledgement}

This research did not receive any specific grant from funding agencies in the public, commercial, or not-for-profit sectors.

\section{References}

[1] Abramovitz L, Lev R, Fuss Z, Metzger Z. 2001. The unpredictability of seal after post space preparation: A fluid transport study. Journal of endodontics. 27(4):292-295.

[2] https://doi.org/10.1097/00004770-200104000-00016.

[3] Asmussen E, Peutzfeldt A, Sahafi A. 2005. Finite element analysis of stresses in endodontically treated, dowel-restored teeth. The Journal of prosthetic dentistry. 94(4):321-329. https://doi.org/10.1016/j.prosdent.2005.07.003.

[4] Balkaya MC, Birdal IS. 2013. Effect of resin-based materials on fracture resistance of endodontically treated thin-walled teeth. The Journal of prosthetic dentistry. 109(5):296-303. https://doi.org/10.1016/S0022-3913(13)60304-2.

[5] Balkenhol M, Wostmann B, Rein C, Ferger P. 2007. Survival time of cast post and cores: A 10-year retrospective study. Journal of dentistry. 35(1):50-58. https://doi.org/10.1016/j.jdent.2006.04.004.

[6] De Castro Albuquerque R, Polleto LT, Fontana RH, Cimini CA. 2003. Stress analysis of an upper central incisor restored with different posts. Journal of oral rehabilitation. 30(9):936-943. https://doi.org/10.1046/j.1365-2842.2003.01154.x.

[7] Dejak B, Mlotkowski A. 2011. Finite element analysis of strength and adhesion of cast posts compared to glass fiber-reinforced composite resin posts in anterior teeth. The Journal of prosthetic dentistry. 105(2):115-126 https://doi.org/10.1016/S0022-3913(11)600115 .

[8] Durmus G, Oyar P. 2014. Effects of post core materials on stress distribution in the restoration of mandibular second premolars: A finite element analysis. The Journal of prosthetic dentistry. 112(3):547-554 https://doi.org/10.1016/S0022-3913(11)60011-5.

[9] Fu G, Deng F, Wang L, Ren A. 2010. The three-dimension finite element analysis of stress in posterior tooth residual root restored with postcore crown. Dental traumatology: official publication of International Association for Dental Traumatology. 26(1):64-69. https://doi.org/10.1111/j.1600-9657.2009.00829.x.
[10] Genovese K, Lamberti L, Pappalettere C. 2005. Finite element analysis of a new customized composite post system for endodontically treated teeth. Journal of biomechanics. 38 (12):2375-2389. https://doi.org/10.1016/j.jbiomech.2004.10.009.

[11] Gonzalez-Lluch C, Rodriguez-Cervantes PJ, Sancho-Bru JL, PerezGonzalez A, Barjau-Escribano A, Vergara-Monedero M, FornerNavarro L. 2009. Influence of material and diameter of prefabricated posts on maxillary central incisors restored with crown. Journal of oral rehabilitation. 36 (10):737-747. https://doi.org/10.1111/j.1365-2842.2009.01989.x.

[12] Katranji A, Misch K, Wang HL. 2007. Cortical bone thickness in dentate and edentulous human cadavers. Journal of periodontology. 78(5):874-878. https://doi.org/10.1902/jop.2007.060342.

[13] Li X, Shi Y, Li Z, Song C, Chen X, Guan Z, al. e. 2008. Threedimensional finite element analysis of a maxillary central incisor restored with different post-core materials. Int Chin J Dent. 8:2127. http://www.kssfp.jp/icjd/june08vo8issue2_p02

[14] Mahmoudi M, Saidi A, Gandjalikhan Nassab SA, Hashemipour MA. 2012. A three-dimensional finite element analysis of the effects of restorative materials and post geometry on stress distribution in mandibular molar tooth restored with post-core crown. Dental materials journal. 31(2):171-179. https://doi.org/10.4012/dmj.2011-138.

[15] Maroli A, Hoelcher KAL, Reginato VF, Spazzin AO, Caldas RA, Bacchi A. 2017. Biomechanical behavior of teeth without remaining coronal structure restored with different post designs and materials. Materials science \& engineering $\mathrm{C}$, Materials for biological applications. 76:839-844. https://doi.org/10.1016/j.msec.2017.03.152.

[16] Maroulakos G, Nagy WW, Kontogiorgos ED. 2015. Fracture resistance of compromised endodontically treated teeth restored with bonded post and cores: An in vitro study. The Journal of prosthetic dentistry. 114(3):390-397. https://doi.org/10.1016/j.prosdent.2015.03.017.

[17] Nelson SJ, M. AJ. 2010. Wheeler's dental anatomy, physiology and occlusion. Elsevier. 9 ed: pp.99-105. https://www.elsevier.com/books/wheelers-dental-anatomyphysiology-and-occlusion/nelson/978-1-4160-6209-7

[18] Newman MG, Takei H, Klokkevold PR, Carranza FA. 2015. Carranza's clinical periodontology. Elsevier. 12 ed:pp. 27-35. https://www.elsevier.com/books/carranzas-clinicalperiodontology/newman/978-0-323-18824-1

[19] Ortega VL, Pegoraro LF, Conti PCR, Valle AL, Bonfante G. 2004 Evaluation of fracture resistance of endodontically treated maxillary premolars restored with ceromer or heat-pressed ceramic inlays and fixed with dual-resin cements. Journal of oral rehabilitation. 31(4):393-397. https://doi.org/10.1046/j.1365-2842.2003.01239.x.

[20] Oyar P. 2014. The effects of post-core and crown material and luting agents on stress distribution in tooth restorations. The Journal of prosthetic dentistry. 112(2):211-219. https://doi.org/10.1016/j.prosdent.2013.10.024.

[21] Pérez-González A, González-Lluch C, Sancho-Bru JL, RodríguezCervantes PJ, Iserte-Vilar JL. 2011. Biomechanical models of endodontic restorations. Theoretical biomechanics. Vaclav Klika ed, InTech.pp 133-160 https://doi.org/10.5772/24065.

[22] Schwartz RS, Robbins JW. 2004. Post placement and restoration of endodontically treated teeth: A literature review. Journal of endodontics. 30(5):289-301 https://doi.org/10.1097/00004770200405000-00001.

[23] Seo M, Shon W, Lee W, Yoo H-M, Cho B-H, Baek S-H. 2009. Finite element analysis of maxillary central incisors restored with various post-and-core applications. J Korean Acad Conserv Dent. 34(4):324-332. https://doi.org/10.5395/JKACD.2009.34.4.324.

[24] Tang W, Wu Y, Smales RJ. 2010. Identifying and reducing risks for potential fractures in endodontically treated teeth. Journal of endodontics. 36(4):609-617. https://doi.org/10.1016/j.joen.2009.12.002.

[25] Uddanwadiker RV, Padole PM, Arya H. 2007. Effect of variation of root post in different layers of tooth: Linear vs nonlinear finite element stress analysis. Journal of bioscience and bioengineering. 104(5):363-370 https://doi.org/10.1263/jbb.104.363.

[26] Wakabayashi N, Ona M, Suzuki T, Igarashi Y. 2008. Nonlinear finite element analyses: Advances and challenges in dental applications. Journal of dentistry. 36(7):463-471. https://doi.org/10.1016/j.jdent.2008.03.010. 